Document downloaded from:

http://hdl.handle.net/10251/50022

This paper must be cited as:

Dols Ruiz, JF.; Pons Sendra, V.; Alcalá, E.; Valles, B.; Martín, A. (2013). Analysis of dynamic behavior and safety of baby carriages in public transportation buses.

Transportation Research Part A: Policy and Practice. 49:1-9. doi:10.1016/j.tra.2013.01.004.

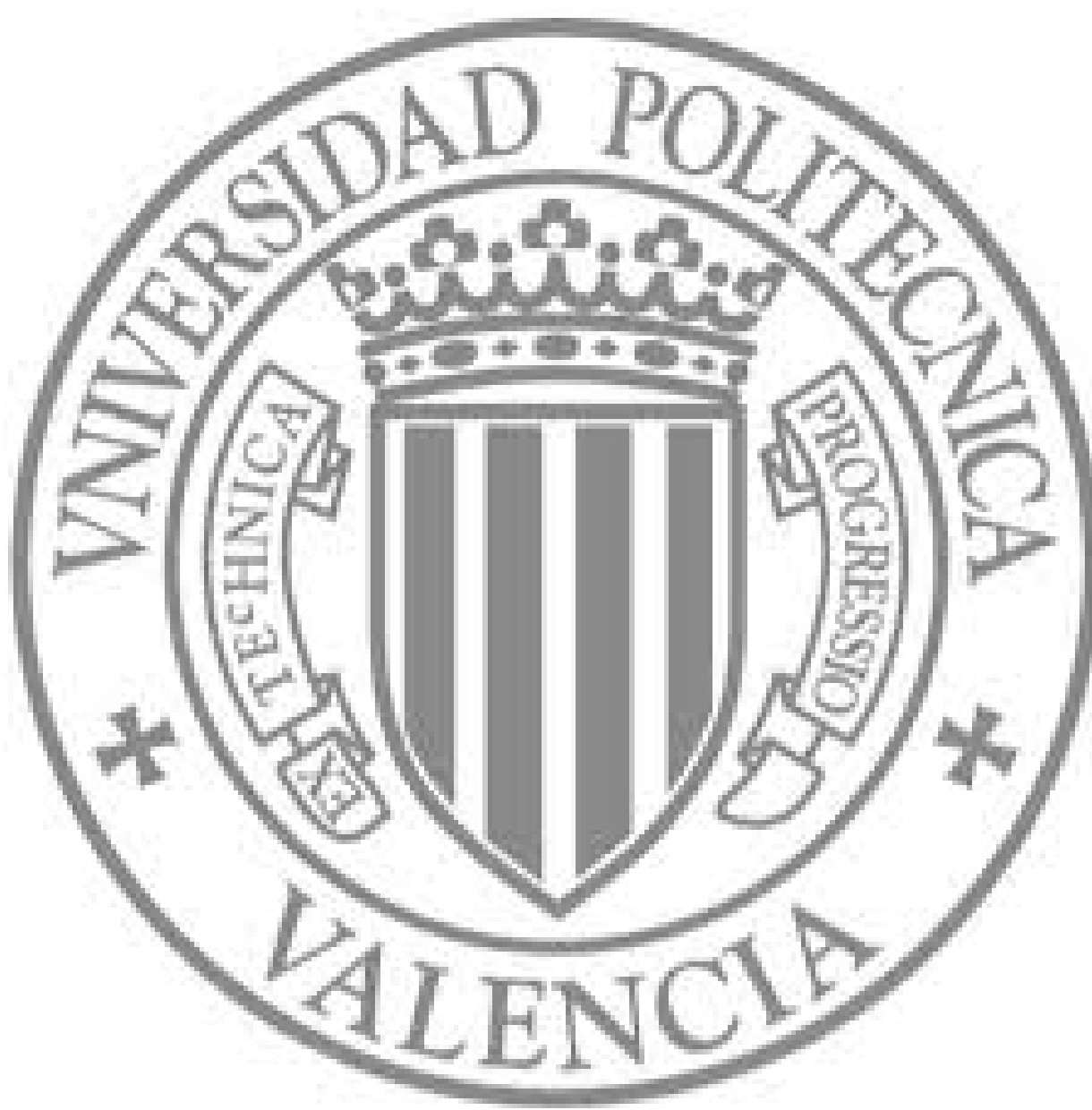

The final publication is available at

http://dx.doi.org/10.1016/j.tra.2013.01.004

Copyright Elsevier 


\title{
Analysis of Dynamic Behavior and Safety of Baby Carriages in Public Transportation Buses
}

\author{
Juan Dols ${ }^{a, 1,{ }^{*}}$, Vicente Pons ${ }^{\mathrm{a}, 1}$, Enrique Alcalá ${ }^{\mathrm{b}, 2}$, Beatriz Valles ${ }^{\mathrm{b}, 2}$, Ángel Martín ${ }^{\mathrm{b}, 2}$ \\ a. Institute of Design and Manufacturing (IDF), Universitat Politècnica de València, Spain. \\ Camino de vera, s/n. 46022 Valencia (Spain) \\ ${ }^{1}$ Tel. +34-963877625 Fax: +34-963879943 \\ Correspondance to 'Email: jdols@mcm.upv.es \\ viponsen@upvnet.upv.es
}

b. University Institute for Automobile Research (INSIA), Universidad Politécnica de Madrid, Spain.

\author{
Campus sur de la UPM, Ctra. De Valencia, km 7. 28031 Madrid (Spain) \\ ${ }^{2}$ Tel. +34-913365303 Fax: +34-913365305 \\ Email: enrique.alcala@upm.es \\ b.valles@upm.es \\ angel.martin@upm.es
}

\begin{abstract}
Issues concerning the use of baby carriages in public buses are still pendant of international legislation that could contribute to unify provisions around accessibility and safety on this type of transportation. There is actually a lack of knowledge around the dynamic behavior and forces involved in the movement of baby carriages when on board in public transportation services. This paper focuses on an analysis of the forces transmitted to the baby carriages and their behavior during normal operation and critical maneuvers by public buses. The article presents partially the results obtained from a research project conducted by the Institute of Design and Manufacturing (IDF) of the Universitat Politècnica de València (Spain) in cooperation with the Institute for Automobile Research (INSIA) of the Universidad Politécnica de Madrid (Spain). The aim was to establish the technical requirements for accessibility and safety of baby carriages (US) or prams (UK) in public buses that could help national and international community to develop standards and provisions on this type of people mobility.

A series of tests with different types of baby carriages were carried out in public transportation buses in closed tracks and open roads to simulate the behavior of critical maneuvers in urban traffic. From an analysis of the testing results it was possible to identify situations where restraint systems should be used, as well as the safest orientation and location within a bus for baby carriages, and enabled the development of a 'Code of Good Practice' for bus operators, users, and baby carriage manufacturers. Furthermore, the analysis of the dynamic forces allowed the development of a new restraint device for securing carriages inside the vehicle's passenger compartment.
\end{abstract}

Keywords: baby carriages, stroller, accessibility, safety, dynamic behavior, public transport. 


\section{INTRODUCTION}

The use of public and private transport is now a fundamental right for all citizens. However, groups of people with reduced mobility (including the disabled who temporarily or permanently use crutches or wheelchairs) as well as the elderly and those travelling with baby carriages or prams, still find difficulties in accessing public transport. Moreover, they may also suffer a reduced level of safety when on board.

Issues concerning the use of baby carriages in public buses are similar to those raised several years ago for the transport of wheelchair users. While the issue of wheelchairs has been resolved with the implementation of European (EC, 2001) or non-European standards (SAE, 1997; ISO, 2001), there aren't currently international standards and regulations governing the safe use of baby carriages on buses. Moreover in most cases upon boarding the bus, children must be removed from their carriages and be held by their parents or guardians. Limited guidelines sometimes exist at a municipal or regional level, but these recommendations have not been based on research finding. In some cases those wishing to leave children in the baby carriage must remain near the front of the bus, or utilizing the people with reduced mobility (PRM) special seats or spaces when available. In other situations at the operator's discretion, baby carriages or strollers that impede the flow of passengers when boarding or exiting, or that are deemed unsafe for transport may be refused entry, as it is the case of twin strollers, used by two children simultaneously, which entry is forbidden in transportation vehicles in the majority of cases. Also mobility-impaired passengers as wheelchair users have priority in the transportation interior space.

There is a lack of knowledge that could contribute to unify provisions on this field, so the need for evaluate normal practices and develop future international policy that help transportation community to understand and solve the problem. These were the reasons that prompted the research project 'Accessibility Requirements and the Safe Use of Baby Carriages in Public Buses' (ASUCAR), funded by the Spanish Ministry of Science and Innovation during 2009-2011 national research program in order to establish the technical requirements for accessibility and safety of baby carriages in public buses.

In this project a pre-competitive statistical analysis was scheduled regarding the conditions of accessibility and the safety of baby carriages in Spanish public buses (Dols et al., 2012) which was produced in collaboration with the Spanish Association of Urban and Road Transport (ATUC). The results revealed that $32 \%$ of the analyzed bus operators applied local accessibility standards, $27 \%$ applied wholly arbitrary internal standards, $11 \%$ applied standards published by regional governments, and $30 \%$ of companies did not apply

any type of regulation. None of the norms analyssed made reference to levels of deceleration and the forces that baby carriages (and their occupants) are subject to under normal operating conditions in a bus when making typical or sudden maneuvers, or the consequences of interference and collisions with other passengers or interior elements, or the consequences of a frontal or side collision of the bus itself.

This paper discusses some of the results obtained in this research project, specifically those analyzing the forces that baby carriages and their occupants are subjected to when travelling on a bus whitout leaving the baby carriage, and the dynamic behavior shown during critical bus maneuvers. The results gave us the possibility for identifying the safest areas of a bus for locating the baby carriages and the most suitable restraint systems. Also the results of the project allowed the development of a 'Code of Good Practice' to be applied for bus operators, users, and baby carriage manufacturers. This code has been established as the basis for the development of Spanish legislation to regulate this type of transport. Furthermore, an analysis of the dynamic forces enabled us the development of a new restraint system for securing carriages inside the passenger compartment. This new system has been protected by patent application No. P201131557. 


\section{METHODOLOGY}

Tests with real vehicles were conducted to analyze the safety and dynamic behavior of baby carriages inside a bus. The aim was to establish the maximum forces to which carriages are submitted and the ideal conditions for their safe transportation. The material used in the tests was a representative selection of baby carriages, a set of test dummies, a representative city bus, and a data acquisition system. A battery of tests was developed for the open road and closed track tests, with various configurations for the positioning of the carriages inside the bus.

\subsection{Description of dynamic testing}

The configuration of the dynamic tests was based on the execution of various typical maneuvers of urban driving (sudden stop, turning tight corners at full speed, and swerving to avoid an obstacle). The tests were reproduced on closed tracks and open roads. Three types of carriage orientation were tested: forward-facing; backward-facing, and sideways to the direction of travel. Three different models of dummies were used in each type of baby carriage - representing different sizes of children and selected according to the type of carriage tested.

Tests reproduced the different behaviors of users when travelling with a baby carriage. Three situations were identified for each one of the carriages tested: wheels freely rotating; brakes applied to the wheels; and the carriage being held by an adult. All trials were recorded with digital cameras fixed in the vehicle for further observation of the behavior of the carriages during the maneuvers. In some trials, simultaneous tests were made with different carriages to lower costs.

The first closed track test was a slalom in which the bus zigzagged at approximately 25 $\mathrm{km} / \mathrm{h}$ between five cones placed 15 meters apart - any faster would have been dangerous for the testers. The second test followed a circular path similar to a large roundabout or traffic circle. Reference standards were applied when performing these tests: SAE J266 (SAE 1996), and the circular test mentioned in the SAE J2181 (SAE 1993). In the circular path test, the steering-wheel of the bus was turned to the maximum, thereby causing a sudden turn with a radius of between 15 and 20 meters. The maximum speed achieved during the test was between 20 and $25 \mathrm{~km} / \mathrm{h}$, given that a higher speed would have been dangerous. The final test performed on a closed track was the emergency stop - in which the driver braked hard while travelling at about $50 \mathrm{~km} / \mathrm{h}$, the maximum speed allowed in urban areas. Close track field testing was developed inside the INSIA facilities at Madrid (Spain) and at the Valencian Public transportation company facilities at Valencia (Spain).

Finally, different open road testing was conducted in the streets of Valencia and Madrid. During these tests, traffic was heavy and vehicle paths were chosen for representing frequent stops for traffic lights, as well as various slopes, tunnels, roundabouts, and raised tram tracks that caused vertical accelerations.

The configurations of the dynamic tests with real vehicles on open roads and closed tracks enabled a battery of 61 trials that reproduced all possible combinations for the various directions of the baby carriages inside the bus (forward-facing, backward-facing, and sidefacing to the direction of travel); wheel braking state on baby carriages (brakes applied and not applied); type of baby carriage; contact between the accompanying adult and the carriage (holding the carriage or free-standing); etc. The slalom test, circular path and the emergency stop were each performed with 17 combinations; while the open road measurements were tested with 10 different combinations.

\subsection{Test dummies}

The trials used three models of dummies representing different ages of children: a newborn dummy for testing flat-bed carriage configurations, a 9-month dummy for testing 
carriages and strollers, and a three-year-old dummy for testing strollers. The newborn and 9month dummies were made to represent the inertial mass equivalent of a newborn $(3.4 \mathrm{~kg})$ and a 9-month baby $(9 \mathrm{~kg})$, and did not contain instrumentation for measuring acceleration, as prescribed in Regulation 44 (ECE, 2008). By contrast, the 3-year-old dummy consisted of a TNO P3 model weighting $15 \mathrm{~kg}$ and contained triaxial accelerometers in the head and chest, as required by the above regulation. The dynamic tests performed with this model were also used to validate the method of analysis of the static stability of the carriages (Alcala et al., 2011), during which a good correlation for dynamic behavior was obtained in the real tests when compared to those in the laboratory.

\subsection{Type of baby carriages used in tests}

During the project some 126 different models of carriages from 26 manufacturers were analyzed. Variables in this study included: type of components mounted on the structure (modular chair, stroller, twin chairs); type of frame (three-wheel stroller, folding rectangle frame, and telescopic post); type of folding frame (umbrella, or book); number of wheels (3, 4 or 6 wheels); and distance between wheels (same or different tracks).

Some other parameters were obtained during this analysis by means of in-situ test at the manufacturers and vendors facilities. General dimensions of the baby carriages were measured, with each of the elements coupled as well as with the carriage folded. It was also measured the tilt angle at witch starts to rollover in lateral, front and rear directions (Alcalá et al., 2010).

The three most representative models of the analyzed sample were finally tested in the open road and close track: namely, those with the worst characteristics in terms of safety and accessibility - or in other words - the heaviest, largest, and least stable. The models selected as the most representative for dynamic testing were the Quinny Buzz, Maclaren Quest, and the Stokke Xplory. Table 1 shows the constructive characteristics of these models.

Table 1.

Constructive characteristics of the carriages used in the tests.

Wrame type




\begin{tabular}{|c|c|c|c|c|}
\hline \multicolumn{2}{|l|}{ Fold } & Book & Umbrella & Book \\
\hline \multicolumn{2}{|c|}{ Length (mm) } & 1050 & 890 & 1130 \\
\hline \multicolumn{2}{|c|}{ Width (mm) } & 655 & 442 & 560 \\
\hline \multicolumn{2}{|c|}{ Height (mm) } & 1105 & 1035 & 1140 \\
\hline \multicolumn{2}{|c|}{ Weight $(\mathrm{kg})^{\star}$} & 15.28 & 6.48 & 13.76 \\
\hline \multicolumn{2}{|c|}{ Front track (mm) } & 292 & 345 & 385 \\
\hline \multicolumn{2}{|c|}{ Rear track (mm) } & 594 & 345 & 510 \\
\hline \multicolumn{2}{|c|}{ Wheelbase (mm) } & 650 & 545 & 625 \\
\hline \multirow{3}{*}{ Folded } & Length (mm) & 1105 & 1040 & 1370 \\
\hline & Width (mm) & 655 & 310 & 560 \\
\hline & Height (mm) & 540 & 270 & 720 \\
\hline
\end{tabular}

* Note: maximum weight between the possible configurations flat-bed, car-seat, or stroller.

\subsection{Data acquisition system}

The signal acquisition system was composed of sensors, an amplifier system with a display and control panel, and a data acquisition system. A Crossbow AHRS400CC triaxial gyroscope with a measuring range of $2 \mathrm{~g}$ was positioned at the center of gravity of the bus. This sensor was used for measuring angles, angular velocities, and accelerations for all three axes. At the center of gravity of the carriages, Kistler K-Beam 8390A10 triaxial accelerometers with a range of $10 \mathrm{~g}$ were positioned. For the acquisition of the physical variables captured by the sensors, an HBM MGCplus AB22A amplifier system was connected to a laptop for configuration, control, and data storage. Several $12 \mathrm{~V}$ batteries were used as a power system for the entire system. Measurements were taken at a sampling frequency of $50 \mathrm{~Hz}$.

\subsection{Vehicle used in dynamic testing}

The buses selected for the trials belonged to $M 3$ cathegory $(E C, 2001)$ and were provided by bus operators in Madrid and Valencia. The specific model was a SCANIA N230 E4 with a CARSA City Versus body. The gross vehicle weight (GVW) was $19,000 \mathrm{Kg}$, the vehicle length was $11.99 \mathrm{~m}$, the width was $2.5 \mathrm{~m}$, and the height was $2.845 \mathrm{~m}$.

\section{RESULTS}

The general dimensions of the baby carriages analysed gave us the possibility for defining the maximum and minimum clearance zones needed for locating the baby carriages folded and unfolded inside the vehicle. The different stroller models studied were classified into two main groups. By one hand the single baby carriage, named as modular-simple stroller, used only by one child, and by the other hand the twin stroller used by two children simultaneously. For both groups were defined the maximum and minimum dimensions length, width and heigth - required inside the bus in case of open or folded stroller. Figure 1 shows results of this data.

The results obtained from the trial testing showed the peak accelerations recorded in each type of test (slalom, circular path and braking) for both the vehicle and the baby carriages. The accelerations are shown in situations where the carriage could move freely and suffered a blow, and in situations where the carriage was restrained and did not suffer a blow. In addition to observing when the carriage remained stable or not during movement of the bus, we calculated the forces that a hypothetical system of restraint must support. The reference 
system was based on ISO 4130 (ISO, 1978). The maximum acceleration values for all the carriage orientations and positions on the bus were recorded for all 61 different trials, in the $\mathrm{X}, \mathrm{Y}$ and $\mathrm{Z}$ axis orientation as ISO 4130 reference system, and calculated as a function of gravity acceleration $\left(1 \mathrm{~g}=9.81 \mathrm{~m} / \mathrm{s}^{2}\right)$. The following table 2 (slalom), table 3 (circular path), table 4 (emergency brake), and table 5 (open road) present the peak values and worst cases measured for each battery.
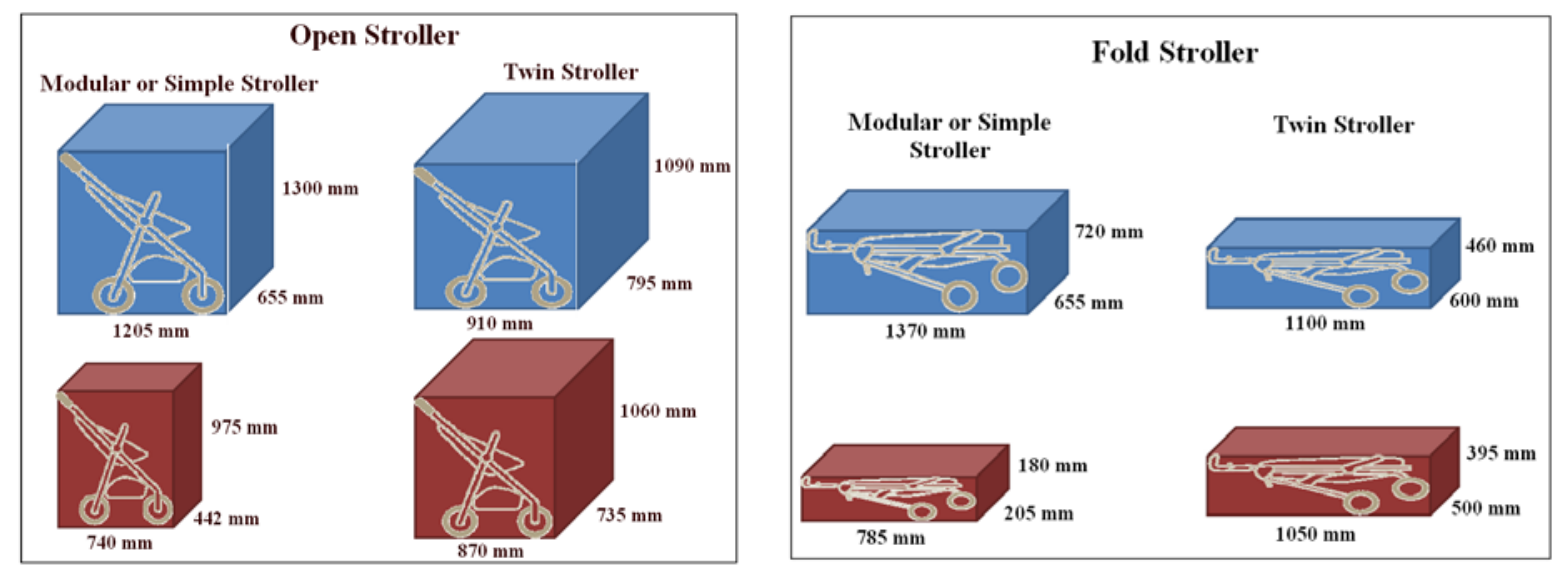

Fig. 1. Maximum and minimum dimensions for clearance zones in open stroller (left) and fold stroller (right) for modular-simple or twin-type baby carriages.

Table 2.

Maximum acceleration during slalom test.

\begin{tabular}{|ccccccc|}
\hline & \multicolumn{3}{c}{ Carriage restrained } & \multicolumn{3}{c|}{ Carriage unrestrained } \\
\hline \multicolumn{3}{c}{ Acceleration $(\mathrm{g})$ units } & \multicolumn{3}{c|}{ Acceleration $(\mathrm{g})$ units } \\
\hline Axis & $\mathrm{X}(\mathrm{g})$ & $\mathrm{Y}(\mathrm{g})$ & $\mathrm{Z}(\mathrm{g})$ & $\mathrm{X}(\mathrm{g})$ & $\mathrm{Y}(\mathrm{g})$ & $\mathrm{Z}(\mathrm{g})$ \\
Vehicle & 0.3055 & 0.3844 & 1.1478 & 0.3055 & 0.3844 & 1.1478 \\
Stoke X-plory & 0.3686 & 0.4179 & 1.2292 & 1.7291 & 1.6014 & 1.9837 \\
Quinny Buzz & 0.2480 & 0.3890 & 1.1976 & 0.6820 & 0.3890 & 1.1976 \\
Maclaren Quest & 0.4184 & 0.4240 & 1.2634 & 0.7968 & 0.4914 & 1.3275 \\
\hline
\end{tabular}

Table 3.

Maximum acceleration during roundabout test.

\begin{tabular}{|ccccccc|}
\hline & \multicolumn{3}{c}{ Carriage restrained } & \multicolumn{3}{c|}{ Carriage unrestrained } \\
\hline \multicolumn{3}{c}{ Acceleration $(\mathrm{g})$ units } & \multicolumn{3}{c|}{ Acceleration $(\mathrm{g})$ units } \\
\hline Axis & $\mathrm{X}(\mathrm{g})$ & $\mathrm{Y}(\mathrm{g})$ & $\mathrm{Z}(\mathrm{g})$ & $\mathrm{X}(\mathrm{g})$ & $\mathrm{Y}(\mathrm{g})$ & $\mathrm{Z}(\mathrm{g})$ \\
Vehicle & 0.4280 & 0.6573 & 1.3665 & 0.4280 & 0.6573 & 1.3665 \\
Stokke Xplory & 0.4342 & 0.6036 & 1.4964 & 1.7079 & 4.9971 & 3.3214 \\
Quinny Buzz & 0.4686 & 0.6709 & 1.3362 & 1.0192 & 0.5811 & 1.2963 \\
Maclaren Quest & 0.4351 & 0.5020 & 1.4567 & 1.0956 & 1.1769 & 1.4153 \\
\hline
\end{tabular}

Table 4.

Maximum acceleration during emergency braking test.

\begin{tabular}{|ccccccc|}
\hline & \multicolumn{3}{c}{ Carriage restrained } & \multicolumn{3}{c|}{ Carriage unrestrained } \\
\hline & \multicolumn{3}{c}{ Acceleration $(\mathrm{g})$ units } & $\mathrm{Acceleration}(\mathrm{g})$ units \\
\hline Axis & $\mathrm{X}(\mathrm{g})$ & $\mathrm{Y}(\mathrm{g})$ & $\mathrm{Z}(\mathrm{g})$ & $\mathrm{X}(\mathrm{g})$ & $\mathrm{Y}(\mathrm{g})$ & $\mathrm{Z}(\mathrm{g})$ \\
Vehicle & 0.8544 & 0.1026 & 1.1328 & 0.8544 & 0.1026 & 1.1328 \\
Stokke Xplory & 1.0823 & 0.3820 & 1.9103 & 2.5593 & 1.8256 & 2.7711 \\
Quinny Buzz & 0.7501 & 0.3580 & 1.8440 & 6.5815 & 2.5043 & 2.7604 \\
Maclaren Quest & 0.8724 & 0.4079 & 1.5753 & 3.7504 & 2.4750 & 3.0334 \\
\hline
\end{tabular}


Table 5.

Maximum acceleration during open street test

\begin{tabular}{|c|c|c|c|c|c|c|}
\hline & \multicolumn{3}{|c|}{ Carriage restrained } & \multicolumn{3}{|c|}{ Carriage unrestrained } \\
\hline & \multicolumn{3}{|c|}{ Acceleration (g) units } & \multicolumn{3}{|c|}{ Acceleration (g) units } \\
\hline Axis & $X(g)$ & $\mathrm{Y}(\mathrm{g})$ & $Z(g)$ & $X(g)$ & $\mathrm{Y}(\mathrm{g})$ & $\mathrm{Z}(\mathrm{g})$ \\
\hline Vehicle & 0.3788 & 0.2957 & 1.3703 & 0.3788 & 0.2957 & 1.3703 \\
\hline Stokke Xplory & 0.2979 & 0.3839 & 1.4152 & 0.6012 & 0.9369 & 2.0537 \\
\hline Quinny Buzz & 0.3433 & 0.2999 & 1.3903 & 1.0853 & 1.1759 & 1.6073 \\
\hline Maclaren Quest & 0.4316 & 0.2866 & 1.5659 & 1.8220 & 1.0133 & 1.8588 \\
\hline
\end{tabular}

\section{DISCUSSION}

The maximum and minimum clearance zones needed for locating the baby carriages unfolded inside the vehicle were applied for identifying possible configurations of transport comparing to up to date legislation as 2001/85/EC bus directive (EC, 2001). This directive establishes at least 2 wheelchair reserved spaces of $1300 \mathrm{~mm}$ length and $750 \mathrm{~mm}$ width in each vehicle. Analysing actual market bus configurations combained to the area needed for wheelchair users and baby carriages clearance zones, it can be defined different scenarios that must face up the bus operators and users, depending on the number of wheelchair spaces occupied. In case of NONE wheelchair space is occupied it could be possible to transport up to two open stroller facing forwards or rearwards. But if there is only ONE wheelchair space occupied - with the user travelling facing rearwards against a back restraint table as 2001/85/EC provisions - only one open stroller could be admitted to the vehicle, in this case travelling facing forward. Finally if both TWO wheelchair spaces are occupied by wheelchair users, it won't be possible to get access to the bus for unfolded baby carriages, unless to fold the stroller and hold up the child in the arms of an attendant. In that case bus operator must provide a reserved space for storing the folded trolley in a safe maner during the trip.

An analysis of the trial testing results reveals the dynamic behavior of the different types of baby carriage with different bus configurations and helps identify the most dangerous scenarios.

The slalom test (Table 2) reveals that when restrained the lightweight Maclaren Quest stroller model (rectangular frame and weighting just $6.48 \mathrm{~kg}$ ) showed the greatest acceleration on all three axes. The average bus acceleration was about $0.35 \mathrm{~g}$ on the $X$ and $Y$ axes. The Maclaren Quest also revealed the greatest acceleration on the $Z$ axis with $a$ value of $1.263 \mathrm{~g}$. In many of the tests, the carriages overturned or collided with objects in the passenger compartment when they were unrestrained and brakes were not applied. The Stokke Xplory (telescopic post with three wheels) reached acceleration values of $1.72 \mathrm{~g}$ on the $X$ axis and $1.6 \mathrm{~g}$ on the $\mathrm{Y}$ axis.

The videos showed that when carriages were not held by an adult, and were unrestrained and without brakes, they struck dangerously against objects inside the bus. This behavior occurred when the carriages were positioned in any direction and it is therefore recommended that carriages are not left alone in any case without the brakes applied. In the slalom tests, the best results were obtained when the carriages were held by an adult in a direction side-facing to the direction of travel - although in this situation the adult had difficulty maintaining his or her own balance because of the effort required to hold the carriage.

For the maximum lateral accelerations obtained during the circular path test (Table 3 ) it can be seen that the Quinny Buzz model (three-wheeler stroller weighting $15.28 \mathrm{~kg}$ ) showed the greatest acceleration on the $X(0.46 \mathrm{~g})$ and $Y$ axes $(0.67 \mathrm{~g})$ when restrained. The acceleration in this test is generally greater than in the slalom and varies between $0.45 \mathrm{~g}$ and $0.65 \mathrm{~g}$ on the $X$ and $Y$ axes respectively. With respect to the $Z$ axis, we find that the greatest acceleration $(1.49 \mathrm{~g})$ is recorded for the Stokke Xplory (three wheels and telescopic post) carriage. When the Stokke Xplory could travel freely, the acceleration values were much 
greater (reaching up to $5 \mathrm{~g}$ ) and it overturned and struck against objects inside the bus in many tests.

As in the previous case, unrestrained carriages without brakes accelerated dangerously inside the bus and struck interior objects. These trials show that when a carriage is not being restrained by an adult, it moves about and strikes interior elements regardless of the direction in which it is positioned. The Stokke Xplory model is the tallest and therefore the least stable - turning over during various tests. The tests in which an adult holds the carriage while moving in the direction of travel shows that the adult has serious difficulties maintaining stability, as well as moving towards the interior of the bus, and balancing. So the need to be restrained in any way the baby carriage movement.

In the emergency braking test (Table 4) it was seen that the highest values of acceleration for a restrained carriage oscillated around $1 \mathrm{~g}$ for the $X$ axis and corresponded to the Stokke Xplory model (the tallest of the models and weighting $13.76 \mathrm{~kg}$ ). The same model showed the greatest accelerations on the $Z$ axis $(1.91 \mathrm{~g})$. The values along the $Y$ axis were much smaller given that in a braking test the longitudinal acceleration was the greatest.

The acceleration values were much greater when the carriage was unrestrained and it struck violently against objects in the interior and reached accelerations of $6 \mathrm{~g}$. In this test, if the carriage is not held by an adult, the only stable and secure position is facing backwards and resting up against the support provided for wheelchair users. In any other position, the carriage strikes against various obstacles inside the bus and may travel several meters.

Finally, the acceleration values for the open-road tests in city streets with heavy traffic (including roundabouts, uphill slopes over bridges, and downhill slopes into tunnels) were as expected - lower than in those obtained on the closed track. The maximum acceleration for a restrained carriage was recorded for the lightweight Maclaren Quest $(6.48 \mathrm{~kg})$ with 0.43 $\mathrm{g}$ accelerations on the $X$ axis and $1.56 \mathrm{~g}$ on the $Z$ axis. The same model showed the greatest accelerations for the $X$ axis when unrestrained and without brakes applied (1.82g). The Stokke Xplory (the tallest model) showed the greatest acceleration on the $Z$ axis $(2.05 \mathrm{~g})$.

Analysis of the results obtained across the entire battery of tests showed that many of the carriages are more stable when they are facing forwards or backwards, but that in this position, if the carriage is fixed to the vehicle structure, then a harness should be used to hold the child inside the carriage - otherwise the child may be thrown from the carriage.

It has been shown that many carriage models on the market have a tendency to overturn sideways and this may be easily caused by bus maneuvers producing lateral accelerations of less than $5 \mathrm{~m} / \mathrm{s}^{2}(0.5 \mathrm{~g})$. In these situations, some carriage models expose the child to the risk of striking some part of the interior of the bus with his or her head.

Finally, the maximum accelerations generated during critical maneuvers by a bus, enabled a calculation of the maximum resultant forces that a hypothetical retention system should withstand to restrain the carriage and its occupant(s). However, it should be noted that this calculation does not take into account cases in which the carriage strikes an object or falls over. So, the results shown in Table 6 are referred to movements with carriage restrained. In all trials the worst case appeared in the sudden braking test maneuver.

Table 6.

Maximum forces calculated from tests of the baby carriages.

\begin{tabular}{cccc} 
& Stokke Xplory & Quinny Buzz & Maclaren Quest \\
\hline Carriage weight & $15,80 \mathrm{Kg}$ & $13,70 \mathrm{Kg}$ & $6,50 \mathrm{Kg}$ \\
Max. child weight & $20 \mathrm{Kg}$ & $20 \mathrm{Kg}$ & $15 \mathrm{Kg}$ \\
Max. X acceleration & $1,0823 \mathrm{~g}$ & $0,7501 \mathrm{~g}$ & $0,8724 \mathrm{~g}$ \\
Max. Y acceleration & $0,3820 \mathrm{~g}$ & $0,3580 \mathrm{~g}$ & $0,4079 \mathrm{~g}$ \\
Max. Z acceleration & $1,9103 \mathrm{~g}$ & $1,8440 \mathrm{~g}$ & $1,5753 \mathrm{~g}$
\end{tabular}


Max. resultant acceleration

(braking test)

To sum up, the maximum forces that a restraint system would support to hold the heaviest carriage that generates the largest accelerations (the Stokke Xplory) is $782,46 \mathrm{~N}$. By applying a safety factor of two to the carriage-child combination (Alcalá et al., 2011) we can say that a restraint system for the carriage and its occupant should withstand a total force of approximately $\mathbf{1 5 6 5} \mathbf{N}$ to support critical bus maneuvers (excluding collisions).

\section{CONCLUSIONS}

The analysis of the results obtained from dynamic tests that reproduce the motion of a public bus during critical maneuvers (slalom, braking, and cornering) and the accelerations generated on the baby carriages and its occupants, and taking into account the minimum and maximum clearance zones needed for hosting the baby carriages inside the passenger compartment during a trip in a public bus, we have identified the most suitable areas for positioning the carriages - as well as the most suitable restraint systems for each one. Figure 2 shows a picture representative of the passenger's compartment of a bus with three options for positioning carriages within the vehicle.

Area 1 must be the first choice for transporting baby carriages in the passenger compartment of a bus. This area corresponds to the space reserved for wheelchair users and may be used, obviously, when it is free. In this location the carriage should travel facing rearwards, with brakes applied to the wheels and the back leaning against the fitted backrest. It is recommended that a safety belt is used to support the carriage or stroller against the lateral movements experienced during some maneuvers. Figure 3 shows an example of how can be installed such a device in combination with the back restraint plate.

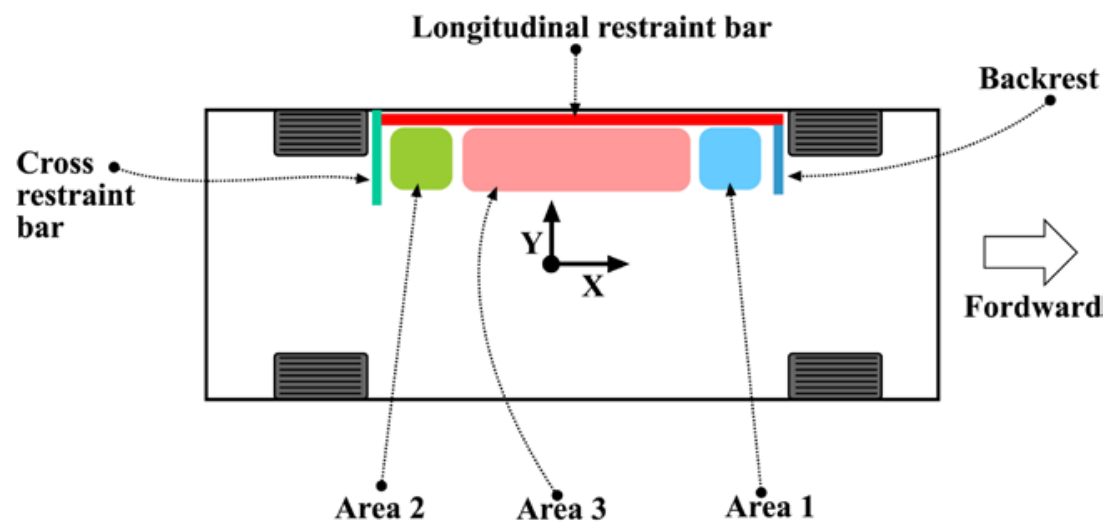

Fig. 2. Preferred zones for baby carriages inside the passenger's compartment of the bus. 


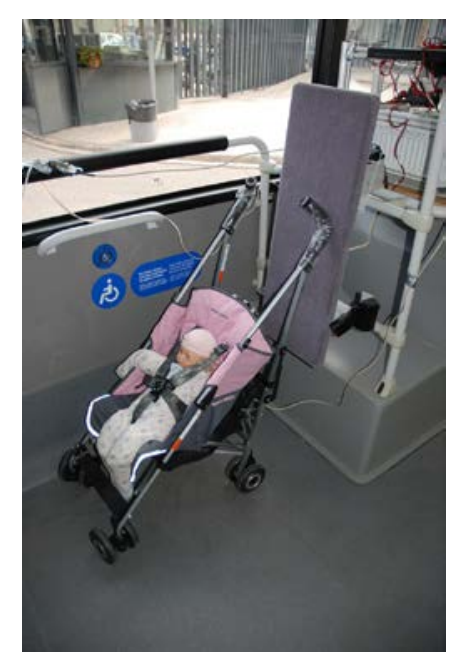

Fig. 3. Baby carriage facing rearwards in Area 1.

A second option would be to locate the baby carriage beside the panel in front of the first row of rear seats (see Figure 2), indicated as Area 2. In this place, the carriage should travel facing forward to the direction of travel and with the brakes applied and the back wheels resting against the separator panel. It is advisable to use a safety belt to support the carriage and prevent any lateral movements during braking. This second option must be picked in case of wheelchair space is occupied by a wheelchair user.

Finally, the third option is to transport the carriage in the area corresponding to Area 3 in Figure 2. This area lies between Areas 1 and 2 - between the space reserved for wheelchair users and the panel separating the first row of rear seats. While this area is found on many buses which passengers compartent is greater than mandated by 2001/85/CE directive, it does not exist on some other buses because of the smallness of the area reserved for the disabled - for not applying the EU bus Directive mandatory only in some EU countries - or the installation of a configuration that favor seating over standing room. To use this area it is necessary to have a restraint system that differs to the system used in the other two areas. Precisely, one of the results of the research project discussed in this paper is based on the development of a new restraint system for holding baby carriages in situations where the area reserved for wheelchair users (area 1) or the area beside the rear panel (area 2) cannot be used, or when the baby carriages is placed in Area 2 facing rearwards to the direction of travel.

This new restraint system has been protected by Spanish patent application P201131557 and its design is based on a folding panel installed on the sidewall of the vehicle. When in rest position the panel folds against the sidewall of the bus (figure $4 \mathrm{a}$ ), and when in use it unfolds at 90 degrees to the wall (figure 4b). Figure 4c shows the restraint in the working position once a lateral wing folds up to 90 degrees to avoid lateral movements onto the baby carriage during vehicle trip. The main advantages of this new system are that it can be adapted to function with different types of buses and most baby carriages on the market. The panel can be mounted on the side wall of a bus in various positions and heights with the aid of embedded guide rails. It has been designed to withstand forces of up to $2 \mathrm{~g}$ and is made of lightweight and durable materials. The system can also be made compatible with various retention systems for wheelchairs. 


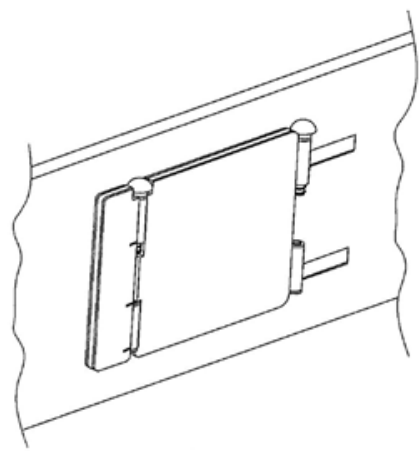

(a)

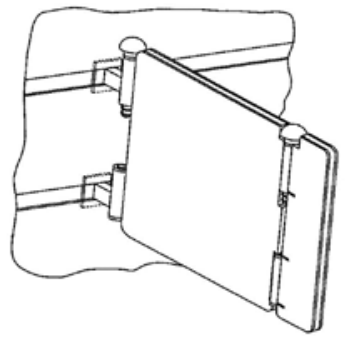

(b)

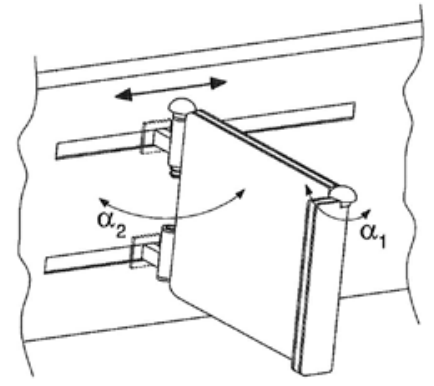

(c)

Fig. 4. Baby carriage restraint system in resting position (a) and working position (c) for area 3 of passenger's compartment of a bus.

The developed restraint system can be implemented in other land transportation systems (rail, tram, metro, etc.) because its simplicity makes it easily adaptable to the passenger compartments of these vehicles. Future research will evaluate the dynamic behavior of the device to the deceleration forces generated in other land-guided vehicles. These forces are expected to be generally lower than those experienced in a bus, which will, in turn, enable a further lightening of the materials used to manufacture the system.

\section{ACKNOWLEDGEMENTS}

The research project 'Accessibility Requirements and the Safe Use of Baby Carriages in Public Buses' (ASUCAR), has been funded by the Spanish Ministry of Science and Innovation (PET2008_0328) during 2008-2011 National Research Program. Our acknowledgement also to the Public Transportation Operators of Madrid and Valencia (Spain) for their contribution and collaboration in the development of the practical trials scheduled in the project, and Mothercare, Chicco shops, El Corte Inglés and Carrefour for their cooperation for facilitating the material for in-situ test with baby carriages.

\section{REFERENCES}

Alcalá, E.; Aparicio, F.; Martín, A.; Valles, B.; Dols, J.; Terrón, J. (2010). Caracterización de los carritos de transporte de niños para su uso en autobuses y autocares. Proceedings del IX Congreso de Ingeniería del Transporte (CIT 2010). Madrid, Spain.

Alcalá, E.; Martín, A.; Valles, B.; Dols, J.F.; Pons, V. (2011). Kinematics of Children Prams in emergency Maneuvers of Urban Buses. Proceedings 13th EAEC European Automotive Congress. ISBN 978-84-615-1794-7. Valencia, Spain.

Dols, J.; Aparicio, F.; Alcalá, E.; Pons, V., Martínez, L.; Martín, A.L.; Vallés, B. (2012). Código de buenas Prácticas para la Utilización de Carritos de Niños en Vehículos de Transporte Público. Ed. Universidad Politécnica de Valencia. ISBN 978-84-8363-8101. Valencia, Spain.

EC. (2001). DIRECTIVE 2001/85/EC OF THE EUROPEAN PARLIAMENT AND OF THE COUNCIL of 20 November 2001 relating to special provisions for vehicles used for the carriage of passengers comprising more than eight seats in addition to the driver's seat, and amending Directives 70/156/EEC and 97/27/EC. OJ L 42, 13.2.2002.

ISO 10542. (2001). Technical systems and aids for disabled or handicapped persons Wheelchair tiedown and occupant restraint systems. Part 1 to 5.

ISO 4130. (1978). Road vehicles. Three-dimensional Reference System and Fiducial Marks. 
Definitions.

ECE R44, rev. 2. (2008). Uniform provisions concerning the approval of restraining devices for child occupants of power-driven vehicles - child restraint system. Geneve. DOE 04.02.2008.

SAE J2249. (1997). Wheelchair tiedown and occupant restraint for use in motor vehicles.

SAE J266. (1996). Steady-State Directional Control Test Procedures for Passenger Cars and Light Trucks.

SAE J2181. (1993). Steady-State Circular Test Procedure for Trucks and Buses. 